\title{
GERMINAÇÃO DE SEMENTES E DESENVOLVIMENTO INICIAL DE PLÂNTULAS DEPhysalis peruviana L. SUBMETIDAS AO ESTRESSE SALINO INDUZIDO POR DIFERENTES TIPOS DE SAIS
}

\author{
Karolini da Silva Cruz; ; Mara Kallyne Alves do Nascimento;Tamara Torres Tanane \\ Claudinéia Regina Pelacani $\mathrm{Cruz}^{3}$ \\ 1. Bolsista PROBIC/UEFS, Graduando em Agronomia, Universidade Estadual de Feira de Santana, e-mail: \\ karlsilvacruz@ hotmail.com \\ 2. Participante do projeto, Programa de Pós-Graduação em Recursos Genéticos Vegetais, Universidade Estadual de \\ Feira de Santana, e-mail: kallyne.alves@hotmail.com;tamara.tanan@yahoo.com.br \\ 3. Orientadora, Departamento de Ciências Biológicas, Universidade Estadual de Feira de Santana, e-mail: \\ claudineiapelacani@gmail.com
}

PALAVRAS-CHAVE: uchuva; emergência; salinidade

\section{INTRODUÇÃO}

A Physalis peruviana L. pertecente a família Solanaceae é uma frutífera caracteriza-se pelo sabor doce e alto conteúdo de vitaminas (A, C, ferro e fósforo), sendo o principal grupo de esteróides encontrados no gênero são as fisalinas (TOMASSINI et al., 2000).Caracterizada como uma planta de crescimento indeterminado, necessita de fornecimento constante de água para o crescimento vegetativo e reprodutivo, especialmente na fase de formação dos frutos, garantindo altos rendimentos (FISCHER et al., 2012).

Para que as sementes germinem é necessário que existam condições favoráveis de luz, temperatura e disponibilidade de água (Carvalho e Nakagawa, 2012).Mas, nem sempre essas condições são adequadas, especialmente em solos salinos e sódicos. A alta concentração de sais é um fator de estresse para as plantas, pois reduz o potencial osmótico e proporciona a ação dos íons sobre o protoplasma. A água é osmoticamente retida na solução salina, de forma que o aumento da concentração de sais a torna cada vez menos disponível para as plantas (Ribeiro et al., 2001). A adaptação das plantas a esse estresse vem sendo avaliada pela capacidade germinativa das sementes e pela análise de crescimento.

Deste modo, este trabalho tem como objetivo avaliar o desenvolvimento pósseminal, as taxas e velocidades de emergência, e o crescimento inicial de Physalis peruviana, sob efeito do estresse salino induzido por diferentes tipos de sais $(\mathrm{NaCl}$, $\mathrm{KCl}, \mathrm{CaCl}^{2}$ e $\mathrm{MgCl}^{2}$ ).

\section{MATERIAL E MÉTODOS}

O experimento foi realizado na Unidade Experimental Horto Florestal, localizada em Feira de Santana-BA. As sementes de Physalis peruviana foram retiradas dos frutos e foram colocadas para secar em incubadora saturada com cloreto de cálcio a $20^{\circ} \mathrm{C}$, por 24 horas, até equilíbrio da umidade e armazenadas em geladeira até o momento dos ensaios (Souza, 2015).

Para a análise de germinação, as sementes foram distribuídas em placas de Petri contendo ao fundo duas folhas de papel do tipo germitest umedecidas com as soluções salinas. Utilizou-se o fatorial 4 x 5, onde o primeiro fator são os tratamentos, constituídos de quatro sais $\left(\mathrm{NaCl}, \mathrm{KCl}, \mathrm{CaCl}^{2}\right.$ e $\left.\mathrm{MgCl}^{2}\right)$, e o segundo fator são concentrações $(0 ; 50 ; 100 ; 150$ e $200 \mathrm{mM})$, no tratamento controle $(0 \mathrm{mM})$ foi utilizado somente água destilada. Para cada tratamento, foram utilizadas 200 sementes, distribuídas em quatro repetições de 50 sementes e conduzidas em germinador com 
fotoperíodo de 12 horas ajustados na temperatura alternada $20-30^{\circ} \mathrm{C}$ (Souza, 2015) por um período de até 30 dias.

A contagem da germinação foi realizada diariamente, considerando-se germinadas as sementes que apresentaram protrusão radicular com pelo menos $2 \mathrm{~mm}$ de comprimento (Souza, 2012). A partir dos dados obtidos foi calculada: a porcentagem de germinação das sementes $(\% \mathrm{G})$, a frequência relativa da germinação (FR\%) e o tempo médio de germinação (TMG).

Foi também avaliado o crescimento inicial das plantas, para isso, foram semeadas sementes de $P$. peruviana em copos plásticos, contendo substrato, com irrigação diária com as soluções salinas $\left(\mathrm{NaCl}, \mathrm{KCl}, \mathrm{CaCl}^{2}\right.$ e $\left.\mathrm{MgCl}^{2}\right)$ nas concentrações de 0,50 e $10 \mathrm{mM}$, até o início da emergência. Após 40 dias da semeadura, as plântulas foram retiradas para realização da análise de crescimento. Foi medida a altura da planta, o comprimento da raiz, o número de folhas, o diâmetro do caule, a área foliar.

O delineamento experimental utilizado foi inteiramente casualizado e os dados foram submetidos à análise devariância, com as médias comparadas pelo teste Tukey de probabilidade a $5 \%$, e a análise de regressão para as diferentes concentrações de sais.

\section{RESULTADOS ALCANÇADOS E DISCUSSÃO}

Os resultados obtidos no teste de germinação demonstram a sensibilidade das sementes de $P$. peruviana a maiores concentrações salinas, visto que para todos os sais avaliados houve redução da $\% \mathrm{G}$ a medida que aumentou a concentração (Figura 1).O $\mathrm{MgCl}^{2}$ foi o sal que proporcionou maior germinação das sementes no tratamento de $200 \mathrm{mM}(39,8 \%)$.

Nenhum dos sais chegou a inibir totalmente o processo de germinação, mas prolongou o tempo médio de germinação (Figura 1). A quantidade de solutos em uma solução, ao reduzir ou aumentar o potencial osmótico do meio, aumenta o tempo necessário para a absorção de água pelas sementes (Pacheco et al., 2012), o que ocasiona o prolongamento do período de germinação.

Levando em consideração que o processo germinativo não ocorre de forma sincronizada, e sim ao longo do tempo (Oliveira et al., 2017), a frequência de germinação também está relacionada ao tempo médio de germinação. A análise dos polígonos possibilitou verificar que a exposição das sementes de Physalis peruviana às fontes de cloreto levou a um deslocamento dos picos para a direita, na maior concentração salina $(200 \mathrm{mM})$, exceto para $\mathrm{MgCl}_{2}$, evidenciando que na maior concentração as sementes levaram mais tempo para iniciar a germinação (protrusão da radícula).

Ao analisar os parâmetros de crescimento como altura, diâmetro do caule, comprimento de raiz, área foliar e número de folhas observa-se comportamento semelhante, com redução significativa a partir da concentração de $50 \mathrm{mM}$ para todos os sais (Tabela 1), indicando que o desenvolvimento da plântula como um todo foi afetado pela solução salina. $\mathrm{O}$ crescimento de $P$. peruviana foi inferior quando submetidas à $\mathrm{NaCl}, \mathrm{CaCl}^{2}$ (sem emergência para ambos os sais) e $\mathrm{KCl}$ na menor concentração. 

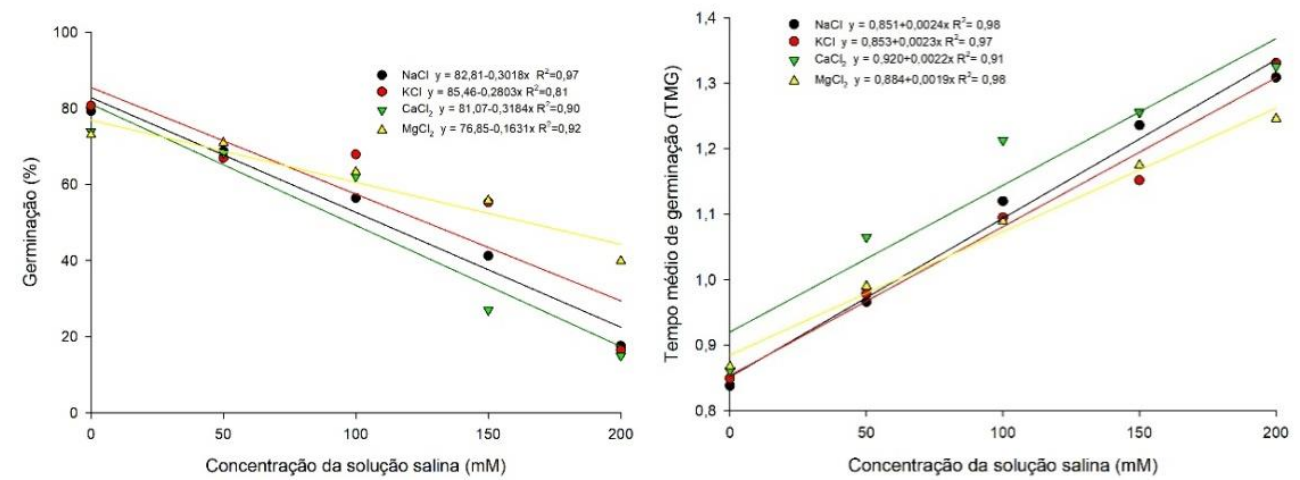

Figura 1. Porcentagem de germinação $(\% \mathrm{G})$ e tempo médio de germinação (TMG) de sementes de Physalis peruviana L. submetidas a diferentes sais em diferentes concentrações. Feira de Santana- BA, 2017
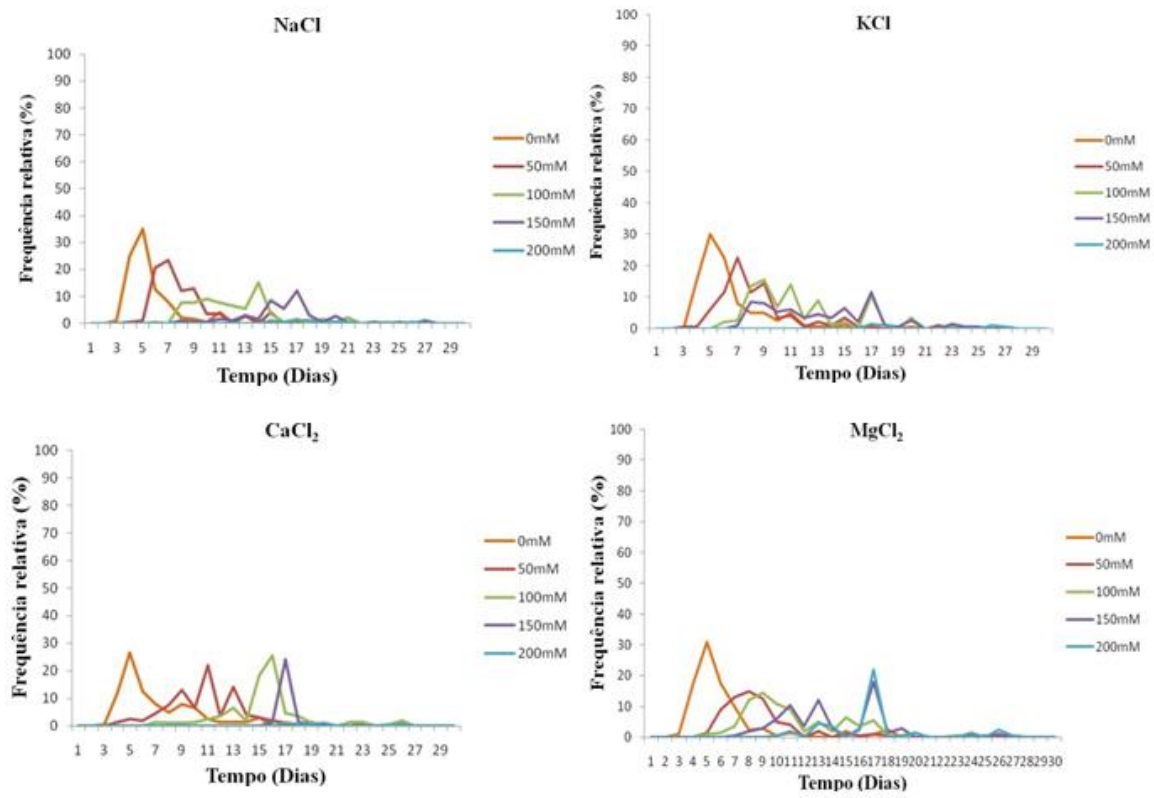

Figura 2. Polígonos de frequência relativa da germinação de sementes de Physalis peruviana submetidas a diferentes soluções salinas.

Em uma observação geral do crescimento das plantas, foi observado uma queda dos valores para os parâmetros de crescimento avaliados com o aumento das concentrações salinas,independente do sal utilizado. Esse fato indica a sensibilidade da espécie à redução da disponibilidade hídrica, pois sabe-se que a medida que ocorre o aumento das concentrações salinas, o potencial osmótico é reduzido, o que prejudica a absorção da água disponível pelas sementes e posteriormente pelas raízes.

Tabela 1. Altura (AP), diâmetro do caule (DC), comprimento da raiz (CR), número de folha (NF) e área foliar (AF) de plantas de $P$. peruviana submetida a diferentes sais e concentrações salinas.

Concentração (mM)

\begin{tabular}{lcrc}
\cline { 2 - 4 } Tratamento & $\mathbf{0}$ & $\mathbf{5 0}$ & $\mathbf{1 0 0}$ \\
\hline $\mathbf{N a C l}$ & $\mathbf{A P}(\mathbf{c m})$ & \\
$\mathbf{K C l}$ & $2,63 \mathrm{Aa}$ & $1,94 \mathrm{Ab}$ & $1,47 \mathrm{Bc}$ \\
$\mathbf{C a C l}$ & $2,63 \mathrm{Aa}$ & $1,96 \mathrm{Ab}$ & \\
$\mathbf{M g C l}_{2}$ & $2,63 \mathrm{Aa}$ & $1,85 \mathrm{Ab}$ & $1,90 \mathrm{Ab}$ \\
\hline
\end{tabular}




\begin{tabular}{|c|c|c|c|}
\hline \multicolumn{4}{|c|}{ DC (mm) } \\
\hline $\mathrm{NaCl}$ & $2,00 \mathrm{Aa}$ & $1,64 \mathrm{Ab}$ & \\
\hline KCl & $2,00 \mathrm{Aa}$ & $1,62 \mathrm{Ab}$ & $1,31 \mathrm{Bc}$ \\
\hline $\mathrm{CaCl}_{2}$ & $2,00 \mathrm{Aa}$ & $1,49 \mathrm{Bb}$ & \\
\hline $\mathrm{MgCl}_{2}$ & $2,00 \mathrm{Aa}$ & $1,54 \mathrm{Bb}$ & $1,44 \mathrm{Ac}$ \\
\hline \multicolumn{4}{|c|}{ CR $(\mathbf{c m})$} \\
\hline $\mathrm{NaCl}$ & $5,20 \mathrm{Aa}$ & $4,57 \mathrm{Ab}$ & \\
\hline KCl & $5,20 \mathrm{Aa}$ & $4,53 \mathrm{Ab}$ & $2,39 \mathrm{Bc}$ \\
\hline $\mathrm{CaCl}_{2}$ & $5,20 \mathrm{Aa}$ & $3,36 \mathrm{Bb}$ & \\
\hline $\mathbf{M g C l}_{2}$ & $5,20 \mathrm{Aa}$ & $3,71 \mathrm{Bb}$ & $3,45 \mathrm{Ab}$ \\
\hline \multicolumn{4}{|c|}{ NF } \\
\hline $\mathrm{NaCl}$ & 2,61 Aa & $2,16 \mathrm{Bb}$ & \\
\hline $\mathrm{KCl}$ & $2,61 \mathrm{Aa}$ & $2,11 \mathrm{Bb}$ & $2,14 \mathrm{Ab}$ \\
\hline $\mathrm{CaCl}_{2}$ & $2,61 \mathrm{Aa}$ & $2,36 \mathrm{Ab}$ & \\
\hline $\mathbf{M g C l}_{2}$ & $2,61 \mathrm{Aa}$ & $2,29 \mathrm{Bb}$ & $1,96 \mathrm{Ac}$ \\
\hline \multicolumn{4}{|c|}{$\mathrm{AF}\left(\mathrm{cm}^{2}\right)$} \\
\hline $\mathrm{NaCl}$ & $4,41 \mathrm{Aa}$ & $2,89 \mathrm{Ab}$ & \\
\hline $\mathrm{KCl}$ & $4,41 \mathrm{Aa}$ & $2,94 \mathrm{Ab}$ & $1,58 \mathrm{Bc}$ \\
\hline $\mathrm{CaCl}_{2}$ & 4,41 Aa & $2,16 \mathrm{Bb}$ & \\
\hline $\mathrm{MgCl}_{2}$ & $4,41 \mathrm{Aa}$ & $2,45 \mathrm{Bb}$ & $2,05 \mathrm{Ac}$ \\
\hline
\end{tabular}

\section{CONSIDERAÇÕES FINAIS}

A germinação das sementes de Physalis peruviana L., foi prejudicada com aumento das concentrações dos sais, sendo o resultado mais acentuado na concentração de $150 \mathrm{mM}$. A queda mais acentuada ocorreu com o aumento das concentrações do $\mathrm{NaCL}$ e $\mathrm{CaCl}^{2}$.

As plantas jovens de P. peruviana são tolerantes ao cloreto de magnésio e devese evitar fontes de cloreto de sódio e cálcio na concentração de $100 \mathrm{mM}$ quando se pretende avaliar potencial de cultivo.

\section{REFERÊNCIAS}

CARVALHO, N.M.; NAKAGAWA, J. Sementes: ciência, tecnologia e produção. 4.ed. Jaboticabal: FUNEP, 2000. 4.ed. Jaboticabal: FUNEP, 2000. 588p.

FISCHER, G.; MIRANDA, D.; PIEDRAHÍTA, W.; ROMERO, J. Avances en cultivo, poscosecha y exportación de la uchuva (Physalis peruvianaL.) en Colombia. Bogotá:

Universidad Nacional de Colombia, 2012. 221p

OLIVEIRA, J D de; Silva, J B da; ALVES, C Z. Tratamentos para incrementar, acelerar e sincronizar a emergência de plântulas de mucuna-preta. Revista Ciência Agronômica, v. 48, n. 3, p. 531-539, jul-set, 2017.

PACHECO, M.V.; FERRARI, C.E.S.; BRUNO, R.L.A.; ARAÚJO, F.S.; SILVA, G.Z.; ARRUDA, A.A. Germinação e vigor de sementes de Capparis flexuosa L. submetidas ao estresse salino. Revista Brasileira de Ciências Agrárias, v. 7, n.2, 2012.

SOUZA, C. L. M. Armazenamento de sementes e caracterização morfofisiológica de espécies do gênero Physalis. Tese de doutorado em recursos genéticos vegetais. UEFS, Feira de Santana, BA, Brasil. 2015.

SOUZA, A.Y.; PEREIRA, A.L.; SILVA, F.F.S DA,; RIBEIRO-REIS, R.C.; EVANGELISTA, M.R.V.; CASTRO, R.D DE.; DANTAS, B.F.; Efeito da salinidade na germinação de sementes e crescimento inicial de mudas de pinhão-manso. Revista Brasileira de Sementes, v.32, n.2, p. 083-092, 2010.

TOMASSINI, T.C.B.; BARBI, N.S.; RIBEIRO, I.V. Gênero Physalis uma revisão sobre vitaesteróides. Química Nova, São Paulo, v.23, n.1, p.47-57, 2000. 